\title{
Uso de bioestimulantes no crescimento de plantas de soja
}

\section{Using biostimulants growth of soybean Glycine max $(\boldsymbol{L}$.}

\author{
Valdere Martins dos Santos ${ }^{1 *}$; Aurélio Vaz de Melo ${ }^{2}$; Dione Pereira Cardoso ${ }^{3}$; André Henrique Gonçalves ${ }^{4}$; Daniela de \\ Cássia Vieira de Sousa ; Átila Reis da Silva ${ }^{6}$
}

Resumo: Na agricultura atual, o uso de produtos bioestimulantes, tornou-se uma opção viável e econômica, para a obtenção de altos rendimentos e melhorias na qualidade do produto. Embora, poucos estudos tenham abordado, o efeito dos bioestimulantes sobre os aspectos biométricos. Portanto, objetivou-se avaliar o uso de bioestimulantes, isolados e combinados, no desempenho agronômico de plantas de Glycine max (L.). O experimento foi conduzido em casa de vegetação na Universidade Federal do Tocantins, Gurupi-TO. Os tratamentos foram constituídos por três bioestimulantes (BU-RG, BU-EC e BU-VG) utilizados em aplicações de três maneiras (via semente, via foliar e combinados). O delineamento experimental utilizado foi em blocos casualizados, com quatro repetições. Foram avaliadas as seguintes características; altura das plântulas, diâmetro do caule, massa seca de folhas, massa seca de caule, massa seca de raízes e volume do sistema radicular. O bioestimulante BU-EC aplicado via semente apresentou a maior taxa de crescimento em altura de plântulas. A combinação dos bioestimulantes BURG via semente + BU-VG via foliar, promoveu a maior taxa de acúmulo de massa seca da folha. Na variável massa seca da raiz o tratamento BU-RG via semente $+\mathrm{BU}-\mathrm{EC}$ via foliar promoveram o maior aumento. Os tratamentos $\mathrm{BU}_{-\mathrm{VG}}{ }^{2}$ e $\mathrm{BU}-$ $\mathrm{RG}^{1}+\mathrm{BU}-\mathrm{VG}^{2}$ proporcionam incremento na altura de planta, maior produção de massa seca de raiz e aumento do volume do sistema radicular tanto em aplicação via semente quanto via foliar.

Palavras-chave: Aspectos biométricos; Cultivar P99R01; Tratamento de sementes.

\begin{abstract}
In current agriculture, the use of biostimulant products has become a viable and economical option for high yields and improvements in product quality. Although few studies have addressed the effect of biostimulants on biometric aspects. Therefore, the objective of this study was to evaluate the use of biostimulants, isolated and combined, in the agronomic performance of Glycine $\max (\mathrm{L}$.) plants. The experiment was conducted in a greenhouse at the Federal University of Tocantins, Gurupi-TO. The treatments consisted of three biostimulants (BU-RG, BU-EC and BU-VG) used in three ways applications (via seed, foliar and combined). The experimental design was a randomized block design, with four replications. The following characteristics were evaluated; seedlings height, stem diameter, leaf dry mass, dry stem mass, root dry mass and root system volume. The biostimulant BU-EC applied via seed showed the highest growth rate in height of seedlings. The combination of the BU-RG biostimulants via seed + BU-VG via leaf, promoted the highest rate of leaf dry mass accumulation. In the variable dry mass of the root, the treatment BU-RG via seed + BU-EC via foliar promoted the greater increase. The treatments BU-VG ${ }^{2}$ and $\mathrm{BU}-\mathrm{RG}^{1}+\mathrm{BU}-\mathrm{VG}^{2}$ provide an increase in plant height, greater root dry mass production and root system volume increase both in seed and leaf application.
\end{abstract}

Key words: Biometric aspects; Cultivar P99R01; Seed treatment.

\footnotetext{
*Autor para correspondência

Recebido para publicação em 20/03/2016; aprovado em 11/06/2017

${ }^{1}$ Engenheiro Agrônomo, Mestre em Produção Vegetal, Universidade Federal do Tocantins, Gurupi-TO; valderemartins25@ hotmail.com

${ }^{2}$ Engenheiro Agrônomo, Doutor em Fitotecnia, Professor Adjunto, Universidade Federal do Tocantins; vazdemelo@uft.edu.br

${ }^{3}$ Engenheira Florestal, Doutora em Agronomia, Universidade Federal de Lavras; cardoso.dione@ gmail.com

${ }^{4}$ Engenheiro Agrônomo, Doutor em Produção Vegetal, Universidade Federal do Tocantins; andrehg@uft.edu.br

${ }^{5}$ Engenheira Agrônoma, Universidade Federal do Tocantins; daniela.de@ hotmail.com

${ }^{6}$ Engenheiro Agrônomo, Doutor em Agronomia, Universidade Federal de Goiás; atilareis@ gmail.com
} 


\section{INTRODUÇÃO}

A soja é considerada a cultura de maior importância econômica do Brasil, título esse adquirido em função da mesma ter apresentado nos últimos anos crescimentos constantes nas últimas safras, com uma produção estimada entre 106,4 e 108,6 milhões de toneladas para a safra 2017/2018. A cultura apresenta uma maior liquidez, o que acaba resultando em maiores possibilidades de se obter rendimentos melhores em relação a outas culturas cultivadas no Brasil (CONAB, 2017).

Os aumentos observados na produtividade têm relação direta com os avanços tecnológicos recentes desenvolvidos, as melhorias do ambiente, manejo da cultura, melhoramento genético e maior eficiência dos produtos (MARCON et al., 2017). Dentre as novas tecnologias utilizadas que buscam incrementar a produtividade da cultura da soja, o uso de bioestimulantes vem obtendo grande destaque, essas substâncias que podem ser sintéticas ou naturais, são de fácil aplicação podendo ser ministradas tanto em aplicações no solo, aplicações foliares e no tratamento de sementes (DOURADO NETO et al., 2014).

Os bioestimulantes, podem estimularem o crescimento vegetal mediante uma maior divisão celular, aumentando a capacidade de absorção de nutrientes minerais, essenciais para a produtividade das culturas (CASTRO; VIEIRA, 2001; SILVA et al., 2008; BERTOLIN et al., 2008).

$\mathrm{Na}$ cultura da soja, alguns autores, observaram que os bioestimulantes podem influenciar a germinação, a massa seca das sementes e o crescimento em altura (KLAHOLD et al., 2006; ÁVILA et al., 2008; CAMPOS et al., 2008). Os mesmos autores, também observaram efeito negativo com aplicação de bioestimulantes para a altura de planta, massa seca das folhas e número de vagens por planta.

Há diversos trabalhos com bioestimulantes, porém, necessita verificar a eficiência real destes produtos. São poucas as pesquisas, que abordam os aspectos fisiológicos da planta da soja, relacionados à aplicação de reguladores vegetais (BERTOLIN et al., 2010). Informações relevantes sobre o efeito destes produtos na cultura da soja forneceriam elementos fundamentais para estudos posteriores sobre a utilização agronômica dos reguladores vegetais.

Com base, no fato de a agricultura está em constante processo de obtenção de novos conhecimentos, buscando mediante à pesquisa científica, conhecer os efeitos causados por produtos bioestimulantes, com o intuito de alcançar maior eficiência na produção das culturas agrícolas. Objetivou-se como o presente trabalho, avaliar o uso de bioestimulantes, isolados e combinados, no desempenho agronômico de plantas de Glycine max (L.).

\section{MATERIAL E MÉTODOS}

O experimento foi conduzido em casa de vegetação na Fundação Universidade Federal do Tocantins, Gurupi-TO, localizado a $11^{\circ} 43^{\prime} 45^{\prime}$ 'S e $49^{\circ} 04^{\prime} 07^{\prime}$ ' $\mathrm{W}$, com altitude média de 287 metros, no ano agrícola 2011/12. As sementes de soja, cultivar P99R01, foram plantadas em vasos de polietileno com capacidade para $3 \mathrm{~kg}$ cada, contendo solo classificado como Latossolo Amarelo, textura arenosa.

O delineamento experimental utilizado foi em blocos casualizados, com quatro repetições. Os tratamentos foram constituídos com três bioestimulantes (BU-RG, BU-EC e BUVG) utilizados de forma isolada e em diferentes combinações (Tabela 1), e uma testemunha não tratada (controle).

Tabela 1. Relação dos tratamentos avaliados e produtos (BU-RG, BU-VG e BU-EC), doses em mL do produto por hectare (L $\mathrm{ha}^{-1}$ ) ou L $50 \mathrm{~kg}^{-1}$ sementes, conforme o fabricante.

\begin{tabular}{|c|c|c|c|}
\hline Trat. & Produtos & Forma de aplicação & Doses \\
\hline $\mathrm{T} 1$ & BU-RG ${ }^{1}$ & Sementes & $100 \mathrm{ml} / 50 \mathrm{~kg}$ sementes \\
\hline $\mathrm{T} 2$ & $\mathrm{BU}-\mathrm{VG}^{2}$ & Foliar & $800 \mathrm{~mL} \mathrm{ha}^{-1}$ \\
\hline $\mathrm{T} 3$ & BU-EC ${ }^{1}$ & Semente & $100 \mathrm{ml} / 50 \mathrm{~kg}$ sementes \\
\hline $\mathrm{T} 4$ & Testemunha & & \\
\hline T5 & BU-RG ${ }^{1}+B U-E^{2}$ & Sementes + foliar & $100+200$ \\
\hline T6 & $\mathrm{BU}-\mathrm{RG}^{1}+\mathrm{BU}-\mathrm{VG}^{2}$ & Sementes + foliar & $100+800$ \\
\hline
\end{tabular}

Em tratamento de sementes; ${ }^{(2)}$ Pulverização foliar, as plantas encontravam-se no o estádio V3.

As características dos bioestimulantes utilizados conforme os fabricantes, O BU-RG- é um bioestimulante do sistema radicular, sendo suas principais características; promover um bom desenvolvimento do sistema radicular, garantir um bom crescimento da parte aérea da planta e assegurar um bom rendimento produtivo dos cultivos. Sua composição contém aminoácidos, sulfatos de Zn e Mn, citrato de Fe, ácido bórico, molibdato de amônio e citrato de ferro. $\mathrm{O}$ BU-EC- é formulado a base de extrato de algas marinhas (Ascophyllum nodosum), molibdênio e ácido fosforoso para estimular o desenvolvimento de frutos e corrigir carências de molibdênio. Contém extrato de algas composto de fitohormônios naturais como auxinas, citocininas e giberelinas, que aumentam a fertilidade de gemas produtivas. As algas marinhas podem ser usadas na agricultura na forma de extratos, sendo usadas como fertilizantes bioestimulantes e/ou fitoprotetores, (IRN-Indução de Resistência Natural). Os extratos de algas marinhas atuam na indução de resistência, sendo muito usado em manejo integrado de doenças. O BUVG- é um Fertilizante orgânico obtidos por fermentação biológica natural através de bactéria do gênero
Brevibacterium sp, tem como principais constituintes de suas matérias primas: resíduo orgânico agroindustrial classe " $A$ " (glútem de milho e arroz), aminoácidos (hidrólise enzimática e fermentação bacteriana), fermentação pela bactéria Brevibacterium sp, amoníaco e ácido nítrico.

O solo utilizado no experimento foi previamente corrigido com calcário Filler na dosagem de 1,7 t ha ${ }^{-1}$. Em seguida fez-se a adubação de plantio, que foi calculada levando se em consideração a análise química do solo e as exigências nutricionais da cultura. A quantidade de adubo que foi utilizado em cada vaso de polietileno foi calculada considerando-se o volume de solo contido no vaso de polietileno e relacionando-o com o volume de solo de um hectare, considerando, para tanto, uma camada de solo de $0,20 \mathrm{~m}$, de forma que foramcolocados $1,875 \mathrm{~g} \mathrm{de} \mathrm{P}_{2} \mathrm{O}_{5}, 1,5 \mathrm{~g}$ $\mathrm{K}_{2} \mathrm{O}$ e $0,3 \mathrm{~g}$ de $\mathrm{N}$ em cada vaso de polietileno.

A semeadura foi realizada manualmente. Os bioestimulantes utilizados no tratamento de sementes foram aplicados diretamente sobre as sementes com o auxílio de uma pipeta graduada, antes do plantio. As sementes foram acondicionadas em sacos plásticos transparentes com 
capacidade de $2,0 \mathrm{~kg}$ que foram agitados vigorosamente durante dois minutos. As sementes ficaram em contato com os produtos durante um período de 1 hora. Após a aplicação dos bioestimulantes, as sementes foram inoculadas com inoculante líquido (Bradyrhzobium), especifico para sementes de soja, na dosagem de $400 \mathrm{~mL} 400 \mathrm{~kg}^{-1}$ de sementes.

Foram semeadas cinco sementes por vaso e o desbaste foi realizado aos cinco dias após a emergência das plantas (DAE), deixando-se uma planta por vaso de polietileno, representando uma unidade experimental. Os bioestimulantes utilizados no estádio V3 foram aplicados utilizando-se um pulverizador costal com capacidade de $20 \mathrm{~L}$, dotado de um bico JD - 12P, com um gasto de calda equivalente a $150 \mathrm{~L}$ ha 1 .

Durante a condução do experimento, foram realizados todos os tratamentos fitossanitários necessários para a cultura. As plantas foram irrigadas duas vezes por dia, para manter o solo sempre úmido. Esse procedimento garantiu a disponibilidade hídrica necessária durante todo $\mathrm{o}$ experimento, evitando a restrição ou o excesso de água para as plantas. Os vasos de polietileno apresentavam orifícios no fundo, os quais evitavam o acúmulo de água em eventuais excessos de aplicação.

Foram avaliadas as seguintes características: ALT altura de plântulas, DC - diâmetro de caule, MSF - massa seca das folhas, MSC - massa seca do caule, MSR - massa seca da raiz e VSR - volume do sistema radicular. O experimento foi avaliado em cinco épocas de avaliação $(9,18,27,36$ e 45 dias após a emergência), utilizando o método destrutivo.

Durante as avaliações as plantas foram coletadas e acondicionadas em sacos plásticos e transportadas ao laboratório, onde foram divididas em folha, caule e raiz, para que as avaliações fossem realizadas. A altura das plântulas
(AP) foi determinada, com o auxílio de uma régua milimétrica, medindo-se a distância entre o colo da planta até o ápice. O diâmetro do caule (D) foi medido com o auxílio de um paquímetro digital (Zaas150 mm6“) de aço. Posteriormente, o sistema radicular foi lavado em água corrente.

Em seguida determinou-se o volume do sistema radicular colocando-se as raízes em proveta graduada, contendo um volume conhecido de água. Pela diferença, obteve-se a resposta direta do volume de raízes, segundo metodologia descrita por Basso (1999).

Posteriormente, as diferentes partes da planta foram acondicionadas em sacos de papel e secas em estufas de circulação forçada de ar a $65^{\circ} \mathrm{C}$, até atingirem massa constante. Procedeu-se, então, à determinação da massa seca em balança de precisão, obtendo-se a massa seca de folhas (MSF), a massa seca de caule (MSC), e a massa seca de raízes (MSR).

Os resultados foram submetidos à análise de variância e o teste $\mathrm{F}$, posteriormente, foram ajustadas equações de regressão, ao nível de 5\% de probabilidade, para verificar o comportamento das variáveis, em função das épocas de aplicação dos bioestimulantes. Posteriormente, realizou-se o teste de paralelismo entre as possíveis curvas geradas em função dos dias após o plantio.

\section{RESULTADOS E DISCUSSÃO}

Nos resultados quanto à altura de plântulas (AP), observa-se que o tratamento $\mathrm{BU}-\mathrm{EC}^{(1)}$ apresentou a maior taxa de crescimento em altura $2,11 \mathrm{~cm} \mathrm{dia}^{-1}$, passando de 2,5 $\mathrm{cm}$ aos 9 dias após a emergência para $78,46 \mathrm{~cm}$ na última época de avaliação (Tabela 2).

Tabela 2. As equações de regressão linear e seus respectivos coeficientes de determinação para o efeito da aplicação de bioestimulantes sobre as características ALT - altura da planta, DC - diâmetro do caule e MSF - massa seca da folha, em função das épocas de avaliação.

\begin{tabular}{|c|c|c|}
\hline Tratamentos & Equações de regressão & $\mathrm{R}^{2}$ \\
\hline \multicolumn{3}{|c|}{ ALT - Altura de plântulas } \\
\hline $\mathrm{T} 1$ & $\hat{\mathrm{Y}}_{\mathrm{ALT} 1}=-11,56+1,91 * \mathrm{EP}^{* *}$ & 0,97 \\
\hline $\mathrm{T} 2$ & $\hat{\mathrm{Y}}_{\mathrm{ALT} 2}=-14,52+2,06 * \mathrm{EP}^{* *}$ & 0,96 \\
\hline $\mathrm{T} 3$ & $\hat{\mathrm{Y}}_{\mathrm{ALT} 3}=-16,49+2,11 * \mathrm{EP}^{* *}$ & 0,89 \\
\hline $\mathrm{T} 4$ & $\hat{\mathrm{Y}}_{\mathrm{ALT} 4}=-13,28+1,90 * \mathrm{EP}^{* *}$ & 0,95 \\
\hline $\mathrm{T} 5$ & $\hat{\mathrm{Y}}_{\text {ALT } 5}=-14,00+2,04 * \mathrm{EP}^{* *}$ & 0,93 \\
\hline T6 & $\hat{\mathrm{Y}}_{\mathrm{ALT} 6}=-12,53+1,66 * \mathrm{EP}^{* *}$ & 0,95 \\
\hline \multicolumn{3}{|c|}{ DC - Diâmetro de Caule } \\
\hline $\mathrm{T} 1$ & $\hat{\mathrm{Y}}_{\mathrm{DC} 1}=-0,20+0,01 * \mathrm{EP}^{* *}$ & 0,99 \\
\hline $\mathrm{T} 2$ & $\hat{\mathrm{Y}}_{\mathrm{DC} 2}=-0,20+0,01 * \mathrm{EP}^{* *}$ & 0,98 \\
\hline $\mathrm{T} 3$ & $\hat{\mathrm{Y}}_{\mathrm{DC} 3}=-0,20+0,01 * \mathrm{EP}^{* *}$ & 0,99 \\
\hline $\mathrm{T} 4$ & $\hat{\mathrm{Y}}_{\mathrm{DC} 4}=-0,22+0,01 * \mathrm{EP}^{* *}$ & 0,99 \\
\hline $\mathrm{T} 5$ & $\hat{\mathrm{Y}}_{\mathrm{DC} 5}=-0,23+0,01 * \mathrm{EP}^{* *}$ & 0,97 \\
\hline T6 & $\hat{\mathrm{Y}}_{\mathrm{DC} 6}=-0,24+0,01 * \mathrm{EP}^{* *}$ & 0,97 \\
\hline \multicolumn{3}{|c|}{ MSF - Massa Seca da Folha } \\
\hline $\mathrm{T} 1$ & $\hat{\mathrm{Y}}_{\mathrm{MSF} 1}=-1,55+0,13^{*} \mathrm{EP}^{* *}$ & 0,94 \\
\hline $\mathrm{T} 2$ & $\hat{\mathrm{Y}}_{\mathrm{MSF} 2}=-1,75+0,14 * \mathrm{EP}^{* *}$ & 0,93 \\
\hline $\mathrm{T} 3$ & $\hat{\mathrm{Y}}_{\mathrm{MSF} 3}=-1,64+0,13 * \mathrm{EP}^{* *}$ & 0,91 \\
\hline $\mathrm{T} 4$ & $\hat{\mathrm{Y}}_{\mathrm{MSF} 4}=-1,45+0,12 * \mathrm{EP}^{* *}$ & 0,94 \\
\hline T5 & $\hat{\mathrm{Y}}_{\mathrm{MSF} 5}=-1,38+0,12 * \mathrm{EP}^{* *}$ & 0,94 \\
\hline T6 & $\hat{\mathrm{Y}}_{\mathrm{MSF} 6}=-1,79+0,14 * \mathrm{EP}^{* *}$ & 0,92 \\
\hline
\end{tabular}

$\mathrm{EP}=$ épocas de avaliações; ${ }^{* * *}$ significativo pelo teste " $t$ " a $1 \%$ de probabilidade 
No tratamento $\mathrm{BU}-\mathrm{RG}^{(1)}+\mathrm{BU}-\mathrm{VG}^{(2)}$ foi verificada a menor taxa de crescimento em altura, $1,66 \mathrm{~cm} \mathrm{dia}^{-1}$, aos 9 dias após a emergência esse tratamento estava com $2,41 \mathrm{~cm}$, atingindo $62,17 \mathrm{~cm}$ na última época de colheita, aos 45 dias após a emergência (Figura 1). Quando se realizou o teste de paralelismo verificou-se que apenas os tratamentos BU-RG ${ }^{2} \mathrm{e}$ $\mathrm{BU}-\mathrm{RG}^{1}+\mathrm{BU}-\mathrm{VG}^{2}$ diferiram da testemunha com relação à altura de plantas. Resultados semelhantes foram observados por Campos et al. (2009) ao avaliarem a influência de reguladores vegetais sobre altura de plantas se soja constataram que o tratamento com GA3 (ácido giberélico) via foliar promove o crescimento em altura nas plantas de soja. Porém, Castro e Vieira (2003), trabalhando com aplicações foliares e via semente do bioestimulante aos 15 e $30 \mathrm{DAE}$, na cultura do feijoeiro em vasos, constataram que houve uma redução da altura das plantas em relação ao controle.

Albrecht et al. (2011) avaliaram o manejo na aplicação de biorregulador no desempenho agronômico de plantas de soja em dois anos agrícolas e constaram que não ocorreu efeito significativo em ambos os anos agrícolas para a variável altura de planta.

Com relação ao diâmetro de caule (DC) todos os tratamentos apresentaram a mesma taxa de crescimento de $0,01 \mathrm{~cm} \mathrm{dia}^{-1}$ (Tabela 2). Segundo Moterle et al. (2011) o fato de bioestimulantes afetarem algumas variáveis, mas não afetarem outras, pode ser explicado pela sensibilidade dos tecidos, pelo estádio de desenvolvimento da soja e também pelo efeito cumulativo dos bioestimulantes.

Quanto à massa seca da folha (MSF), de acordo com as equações de regressão ajustadas, os BU-VG ${ }^{(2)}$ e BU-RG ${ }^{(1)}+$ $\mathrm{BU}-\mathrm{VG}^{(2)}$ obtiveram a maior taxa de acúmulo de massa seca da folha, $0,14 \mathrm{~g} \mathrm{dia}^{-1}$, atingindo aos 45 dias após a emergência $4,51 \mathrm{~g} \mathrm{planta}^{-1}$ (Tabela 2). Por outro lado, na testemunha e no tratamento $B U-R^{(1)}+B U-E C^{(2)}$, a menor inclinação da reta significou aumentos menores de massa seca da folha a cada intervalo de tempo $0,12 \mathrm{~g} \mathrm{dia}^{-1}$ (Figura 1). Vieira e Castro (2001), também trabalhando com a cultura da soja conseguiram aumento de 55,3\% na massa seca de plântulas utilizando a concentração de $4,1 \mathrm{ml}$ de bioestimulante diferente do utilizado neste trabalho. Porém Klahold et al. (2006) avaliaram o efeito de bioestimulante aplicado via semente e via pulverização foliar, no desenvolvimento da soja verificaram que para a variável massa seca de folhas não foram verificadas diferenças estatísticas significativas entre os tratamentos com bioestimulante.

Para a variável massa seca do caule (MSC), a maior taxa de acumulo de massa seca do caule foi obtida no tratamento BU-VG ${ }^{(2)}, 0,11 \mathrm{~g} \operatorname{dia}^{-1}$, atingindo aos 45 dias após a emergência 3,34 $\mathrm{g} \mathrm{dia}^{-1}$ (Tabela 3).

Tabela 3. As equações de regressão linear e seus respectivos coeficientes de determinação para o efeito da aplicação de bioestimulantes sobre as características MSC - massa seca do caule, MSR - massa seca da raiz e VSR - volume do sistema radicular, em função das épocas de avaliação.

\begin{tabular}{|c|c|c|}
\hline Tratamentos & Equações de regressão & $\mathrm{R}^{2}$ \\
\hline \multicolumn{3}{|c|}{ MSC - Massa Seca do Caule } \\
\hline $\mathrm{T} 1$ & $\hat{\mathrm{Y}}_{\mathrm{MSC} 1}=-1,38+0,10 * \mathrm{EP}^{* *}$ & 0,90 \\
\hline $\mathrm{T} 2$ & $\hat{\mathrm{Y}}_{\mathrm{MSC} 2}=-1,61+0,11 * \mathrm{EP}^{*}$ & 0,87 \\
\hline $\mathrm{T} 3$ & $\hat{\mathrm{Y}}_{\mathrm{MSC} 3}=-1,47+0,10 * \mathrm{EP}^{*}$ & 0,82 \\
\hline $\mathrm{T} 4$ & $\hat{\mathrm{Y}}_{\mathrm{MSC} 4}=-1,41+0,10 * \mathrm{EP}^{*}$ & 0,88 \\
\hline T5 & $\hat{\mathrm{Y}}_{\mathrm{MSC} 5}=-1,26+0,09 * \mathrm{EP}^{*}$ & 0,89 \\
\hline T6 & $\hat{\mathrm{Y}}_{\mathrm{MSC} 6}=-1,49+0,10 * \mathrm{EP}^{*}$ & 0,86 \\
\hline \multicolumn{3}{|c|}{ MSR - Massa Seca da Raiz } \\
\hline $\mathrm{T} 1$ & $\hat{\mathrm{Y}}_{\mathrm{MSR} 1}=-1,19+0,10 * \mathrm{EP}^{* *}$ & 0,89 \\
\hline $\mathrm{T} 2$ & $\hat{\mathrm{Y}}_{\mathrm{MSR} 2}=-1,35+0,10 * \mathrm{EP}^{*}$ & 0,85 \\
\hline $\mathrm{T} 3$ & $\hat{\mathrm{Y}}_{\mathrm{MSR} 3}=-1,33+0,10 * \mathrm{EP}^{*}$ & 0,84 \\
\hline $\mathrm{T} 4$ & $\hat{\mathrm{Y}}_{\mathrm{MSR} 4}=-1,39+0,10 * \mathrm{EP}^{*}$ & 0,84 \\
\hline $\mathrm{T} 5$ & $\hat{\mathrm{Y}}_{\mathrm{MSR} 5}=-1,47+0,11 * \mathrm{EP}^{*}$ & 0,84 \\
\hline T6 & $\hat{\mathrm{Y}}_{\mathrm{MSR} 6}=-1,34+0,10 * \mathrm{EP}^{*}$ & 0,87 \\
\hline \multicolumn{3}{|c|}{ VSR - Volume do Sistema Radicular } \\
\hline $\mathrm{T} 1$ & $\hat{\mathrm{Y}}_{\mathrm{VSR} 1}=-5,17+0,80 \mathrm{EP}^{* *}$ & 0,93 \\
\hline $\mathrm{T} 2$ & $\hat{\mathrm{Y}}_{\text {VSR } 2}=-3,69+0,74 * \mathrm{EP}^{* *}$ & 0,97 \\
\hline $\mathrm{T} 3$ & $\hat{\mathrm{Y}}_{\mathrm{VSR} 3}=-6,18+0,82^{*} \mathrm{EP}^{*}$ & 0,85 \\
\hline $\mathrm{T} 4$ & $\hat{\mathrm{Y}}_{\mathrm{VSR} 4}=-5,61+0,78 * \mathrm{EP}^{* *}$ & 0,94 \\
\hline $\mathrm{T} 5$ & $\hat{\mathrm{Y}}_{\mathrm{VSR} 5}=-7,0+0,89 * \mathrm{EP}^{* *}$ & 0,90 \\
\hline T6 & $\hat{\mathrm{Y}}_{\mathrm{VSR} 6}=-5,14+0,80 * \mathrm{EP}^{* *}$ & 0,96 \\
\hline
\end{tabular}

$\mathrm{EP}=$ épocas de avaliações; ; significativo pelo teste " $\mathrm{t}$ " a 1\% de probabilidade; * significativo pelo teste "t" a $5 \%$ de probabilidade.

$\mathrm{Na}$ variável massa seca da raiz (MSR), em todos os tratamentos observou-se um aumentou linearmente em função do tempo (Figura 1). Constatou-se maior taxa de crescimento em massa seca da raiz no tratamento $B U-R^{(1)}+B U-E C^{(2)}$ $0,11 \mathrm{~g} \mathrm{dia}^{-1}$. (Tabela 3). Contudo, com relação ao teste de paralelismo apenas o tratamento $B U-V^{2}$ diferiu da testemunha. Os demais tratamentos apresentaram a mesma taxa de crescimento que a testemunha $0,10 \mathrm{~g} \mathrm{dia}^{-1}$. Houve um enovelamento das raízes, porém, não prejudicou o crescimento e desenvolvimento da cultura, pois as mesmas permaneceram em desenvolvimento por um período 45 dias 
após a semeadura, e esse período, não foi suficiente para reduzir a taxa de crescimento do sistema radicular.

Resultados semelhantes foram obtidos por Ferreira et al. (2007) na cultura do milho onde observaram que a utilização de bioestimulantes promoveu um maior acúmulo de massa seca de raízes, em relação á testemunha comprovando o efeito desses produtos sobre o maior desenvolvimento radicular das plantas. Klahold et al. (2006) ao avaliarem o efeito de bioestimulante aplicado via semente e via pulverização foliar, no desenvolvimento da soja, encontraram ganhos significativos para a variável massa seca das raízes na ordem de 35,2 \% em relação á testemunha. Porém, Leite et al. (2003) descrevem que a emergência das plantas de soja e o comprimento das raízes foram reduzidos com o tratamento de sementes com giberelina e citocinina, porém, com desenvolvimento da planta, desapareceu a diferença no crescimento radicular.

Segundo Albrecht et al. (2010) a utilização de bioreguladores podem contribuir para um adequado balanço hormonal das plantas, possibilitando as mesmas um crescimento adequado tanto da parte aérea como do sistema radicular, com bom desenvolvimento de suas estruturas vegetativas e reprodutivas, com seu aparato fotossintético apto a gerar fotoassimilados para incremento na fotossíntese líquida e, assim, permitir maior acúmulo de biomassa e apresentar maior tolerância a estresses ambientais. As maiores taxas de crescimento observadas neste trabalho podem estar relacionadas ao fato de os reguladores de crescimento vegetal possuir papel fundamental na síntese de substâncias de reserva aumentam a absorção e a utilização de nutrientes (CASTRO, 2006).

Com relação ao volume do sistema radicular (VSR), o tratamento $\mathrm{BU}^{-\mathrm{RG}^{(1)}}+\mathrm{BU}^{-\mathrm{EC}^{(2)}}$ apresentou a maior taxa de crescimento, $0,89 \mathrm{~g} \mathrm{dia}^{-1}$. Contudo, apenas o tratamento BU$\mathrm{RG}^{1}+\mathrm{BU}-\mathrm{VG}^{2}$ diferiu da testemunha, independentemente dos possíveis modelos utilizados. Por outro lado, no tratamento $\mathrm{BU}-\mathrm{VG}^{(2)}$ foi verificada a menor taxa de aumento no volume do sistema radicular $0,74 \mathrm{~g} \mathrm{dia}^{-1}$ (Tabela 3). Os reguladores vegetais contidos no bioestimulante BU-RG estão relacionados ao desenvolvimento do sistema radicular podendo possibilitar melhor aproveitamento dos nutrientes contidos no solo.

Figura 1. Efeito do uso de bioestimulantes (a) na altura de plântulas, (b) diâmetro do caule, (c) massa seca da folha, (d) massa seca do caule, (e) massa seca da raiz e (f) volume do sistema radicular, em função dos dias após o plantio. T1 = BU-RG ${ }^{1} ; \mathrm{T}_{2}=$

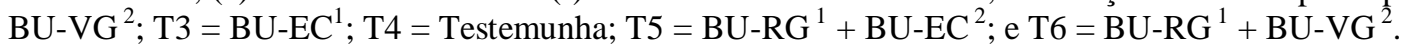
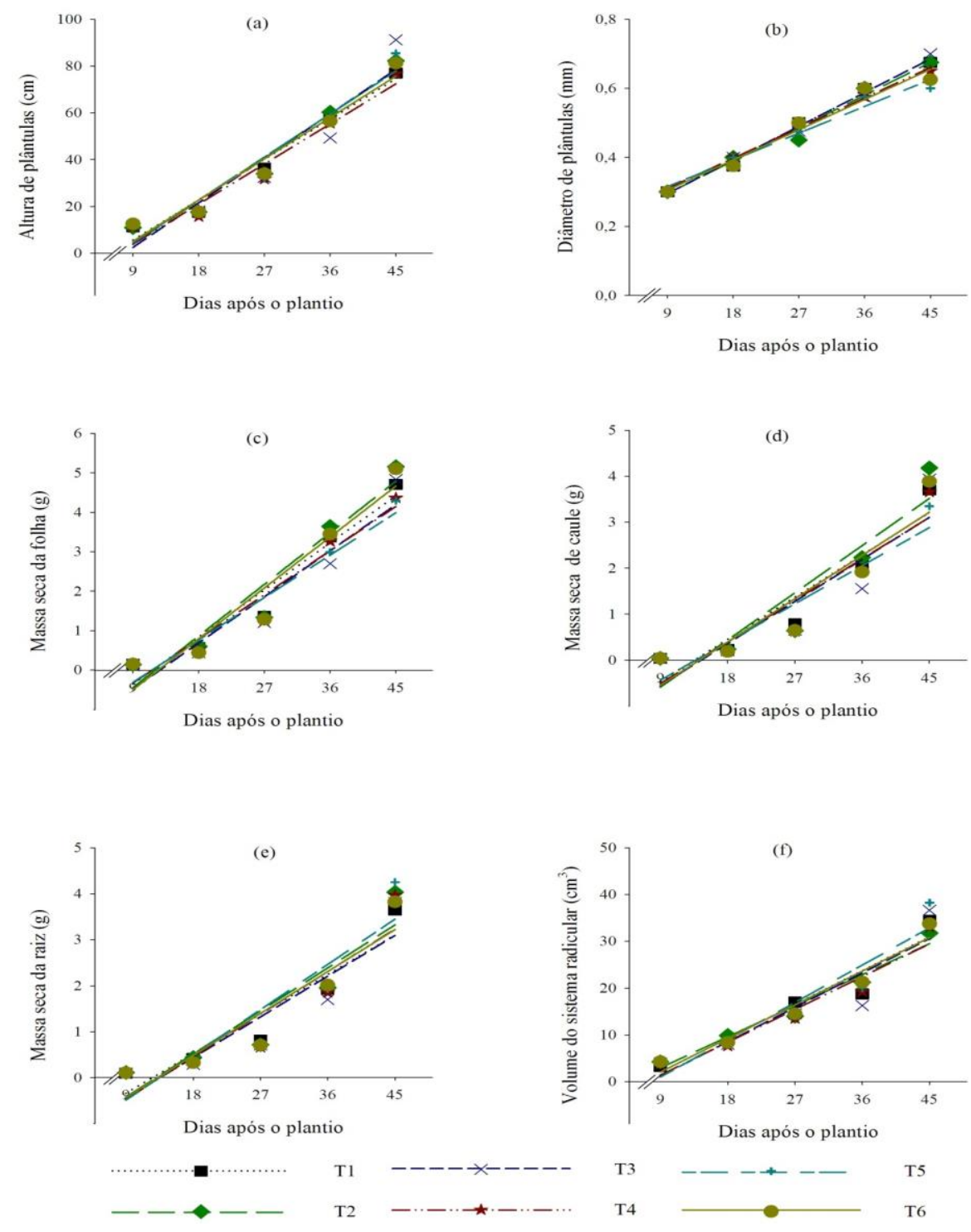
Valdere Martins dos Santos et al.

Vieira e Castro (2001) trabalhando com reguladores de vegetais de ação promotora, na cultura da soja constatou que as plantas tratadas apresentaram um sistema radicular mais desenvolvido, apresentando valores de massa seca superiores aos encontrados nas plantas não tratadas. Castro et al. (2008) ao avaliarem o efeito do tratamento de sementes com inseticidas e um bioestimulante na germinação de sementes de soja, constataram que o tratamento de sementes de soja com o bioestimulante não proporcionaram maior crescimento das raízes.

De acordo com os resultados encontrados neste trabalho, deve-se ressaltar que fatores abióticos podem influenciar sobremaneira a ação dos bioestimulantes nas sementes e a aplicação dos bioestimulantes na superfície das sementes não garante a sua absorção, pelo menos em sua totalidade. Segundo Buchanan et al. (2001) a quantidade de bioestimulantes absorvida depende fundamentalmente da superfície de contato da semente e da quantidade de água e da concentração da solução, contendo os bioestimulantes, absorvida pelas sementes. Assim, a menor absorção dos bioestimulantes pode ter comprometido sua eficiência.

\section{CONCLUSÕES}

Os tratamentos BU-VG e $\mathrm{BU}-\mathrm{RG}^{1}+\mathrm{BU}-\mathrm{VG}^{2}$ proporcionam incremento na altura de planta, maior produção de massa seca de raiz e aumento do volume do sistema radicular tanto em aplicação via semente quanto via foliar.

\section{REFERÊNCIAS}

ALBRECHT, L. P.; BRACCINI, A. L.; SCAPIM, C. A.; ÁVILA, M. R.; ALBRECHT, A. P.; RICCI, T. T. Manejo de biorregulador nos componentes de produção e desempenho das plantas de soja. Bioscience Journal, Uberlândia, v.27, n.6, p.865-876, 2011.

ALBRECHT, L. P.; BRACCINI, A. L.; SCAPIM, C. A.; ÁVILA, M. R.; ALBRECHT, A. J. P.; BARBOSA, M. C. Qualidade das sementes de soja produzidas sob manejo com biorregulador. Revista Brasileira de Sementes, Brasília, v.32, n.4, p.39-48, 2010.

ÁVILA, M. R.; BRACCINI, A. L.; SCAPIM, C. A.; ALBRECHT, L. P.; TONIN, T. A.; STÜLP, M. Bioregulator application, agronomic efficiency, and quality of soybean seeds. Scientia Agricola, Piracicaba, v.65, p.567-691, 2008.

BASSO, S. M. S. Caracterização morfológica e fixação biológica de nitrogênio de espécies de Adesmia DC e Lotus L. 1999. 268 p. Tese (Doutorado)-Universidade Federal do Rio Grande do Sul, Porto Alegre, 1999.

BERTOLIN, D. C.; SÁ, M. E.; ARF, O.; HAGA, K. Y.; ABRANTES, L. F.; NOGUEIRA, D. C. Efeito de bioestimulantes no teor e no rendimento de proteínas de grãos de soja. Agrarian, Dourados, v.1, n.2, p.23-34, 2008.

BERTOLIN, D. C.; SÁ, M. E.; ARF, O.; FURLANI JUNIOR, E.; COLOMBO, A. S.; CARVALHO, F. L. B. M. Aumento da Produtividade de Soja com a Aplicação de Bioestimulantes. Bragantia, Campinas, v.69, n.2, p.339-347, 2010.

BUCHANAN, B. B.; GRUISSEM, W.; JONES R. L. Biochemistry e Molelular: Biology of Plants. American Society of Plant Physiologists, 2001. 1367 p.

CAMPOS, M. F.; ONO, E. O.; BOARO, C. S. F.; RODRIGUES, J. D. Análise de crescimento em plantas de soja tratadas com substâncias reguladoras. Revista Biotemas, Florianópolis, v.21, p.53-63, 2008.

CAMPOS, M. F.; ONO, E. O.; RODRIGUES, J. D. Desenvolvimento da parte aérea de plantas de soja em função de reguladores vegetais. Revista Ceres, Viçosa-MG, v.56, n.1, p.74-079, 2009.

CASTRO, P.R.C.; VIEIRA, E. L. Ação de bioestimulante na cultura do feijoeiro. In: FANCELLI, A.L.; DOURADO NETO, V. (Ed.). Feijão irrigado: tecnologia e produtividade. Piracicaba: Esalq, 2003.

CASTRO, G. S. I. A.; BOGIANI, J. C.; SIlvA, M. G.; GAZOLA, E.; ROSOLEM, C. A. Tratamento de Sementes de Soja com Inseticidas e um Bioestimulante. Pesquisa Agropecuária Brasileira, Brasília, v.43, n.10, p.1311-1318, 2008.

CASTRO, P. R. C; VIEIRA, E. L. Aplicação de reguladores vegetais na agricultura tropical. Guaíba-RS: Agropecuária, 2001. $132 \mathrm{p}$.

CASTRO, P. R. C. Agroquímicos de controle hormonal na agricultura tropical. Piracicaba, (Série Produtor Rural n.32), 2006. 46p.

CONAB. Companhia Nacional de Abastecimento. Acompanhamento da Safra brasileira de Grãos. V. 5 - Safra 2017/18- N. 2 - Segundo levantamento, novembro, 2017.

DOURADO NETO, D.; DARIO, G. J. A.; BARBIERI, A. P. P.; MARTIN, T. N. Ação de bioestimulante no desempenho agronômico de milho e feijão. Bioscience Journal. Uberlândia-MG. v. 30, p. 371-379. 2014.

FERREIRA, L. A.; OLIVEIRA, J. A.; PINHO, E. V. R. V.; QUEIROZ, D. L. Bioestimulante e fertilizante associados ao tratamento de sementes de milho. Revista Brasileira de Sementes, Brasília, v.29, n.2, p.80-89, 2007.

KLAHOLD, C. A.; GUIMARÃES, V. F.; ECHER, M. M.; KLAHOLD, A.; ROBINSON, L. C., BECKER, A. Resposta da soja (Glycine max (L.) Merrill) à ação de bioestimulante. Acta Scientiarum. Agronomy, Maringá, v.28, p.179-185, 2006.

LEITE, V. M.; ROSOLEM, C. A.; RODRIGUES, J. D. Gibberellin and cytokinin effects on soybean growth. Scientia Agricola, Piracicaba, v.60, p.537-541, 2003.

MARCON, E. C.; ROMIO, S. C.; MACCARI, V. M.; KLEIN, C.; LÁJUS, C. R. Uso de diferentes fontes de nitrogênio na cultura da soja. Revista Thema. v. 14. n. 2. pág. 298 a 308. 2017.

MOTERLE, L. M.; SANTOS, R. F.; SCAPIM, C. A.; BRACCINI, A. L.; BONATO, C. M.; CONRADO, T. Efeito de biorregulador na germinação e no vigor de sementes de soja. Revista Ceres, Viçosa-MG, v.58, n.5, p.651-660, 2011.

SILVA, T. T. A.; PINHO, E. R. V.; CARDOSO, D. L.; FERREIRA, C. A.; ALVIM, P. O.; COSTA, A. A. F. Qualidade Fisiológica de Sementes de Milho na Presença de Bioestimulantes. Ciência Agrotecnologia, Lavras, v.32, n.3, p. 840-846, 2008.

VIEIRA, E. L.; CASTRO, P. R. C. Ação de bioestimulante na germinação de sementes, vigor de plântulas, crescimento radicular e produtividade de soja. Revista Brasileira de Sementes, Brasília, v.23, n.2, p. 222-228, 2001. 